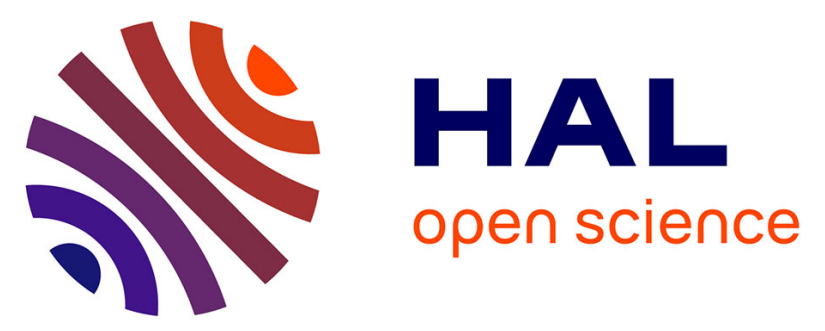

\title{
Phase II study of short-course capecitabine plus oxaliplatin (XELOX) followed by maintenance capecitabine in advanced colorectal cancer: XelQuali study
}

\author{
T. Waddell, S. Gollins, W. Soe, J. Valle, J. Allen, D. Bentley, J. Morris, A. \\ Lloyd, R. Swindell, M. B. Taylor, et al.
}

\section{To cite this version:}

T. Waddell, S. Gollins, W. Soe, J. Valle, J. Allen, et al.. Phase II study of short-course capecitabine plus oxaliplatin (XELOX) followed by maintenance capecitabine in advanced colorectal cancer: XelQuali study. Cancer Chemotherapy and Pharmacology, 2010, 67 (5), pp.1111-1117. 10.1007/s00280-010-1322-0 . hal-00612712

\section{HAL Id: hal-00612712 https://hal.science/hal-00612712}

Submitted on 30 Jul 2011

HAL is a multi-disciplinary open access archive for the deposit and dissemination of scientific research documents, whether they are published or not. The documents may come from teaching and research institutions in France or abroad, or from public or private research centers.
L'archive ouverte pluridisciplinaire HAL, est destinée au dépôt et à la diffusion de documents scientifiques de niveau recherche, publiés ou non, émanant des établissements d'enseignement et de recherche français ou étrangers, des laboratoires publics ou privés. 


\section{Phase II study of short-course capecitabine plus oxaliplatin (XELOX) followed by maintenance capecitabine in advanced colorectal cancer: XelQuali study}

T Waddell T, ${ }^{1}$ S Gollins, ${ }^{2}$ W Soe, ${ }^{1}$ J Valle, ${ }^{1}$ J Allen, ${ }^{1}$ D Bentley,,${ }^{1}$ J Morris, ${ }^{2}$ A Lloyd, ${ }^{2}$ R Swindell, ${ }^{1}$ MB Taylor, ${ }^{1}$ MP Saunders ${ }^{1}$

${ }^{I}$ Christie Hospital, Withington, Manchester, M20 4BX, United Kingdom; ${ }^{2}$ North Wales Cancer Treatment Centre, Glan Clwyd Hospital, Rhyl, LL18 5UJ, United Kingdom

Correspondence:

Dr Mark Saunders

Christie Hospital

Wilmslow Road

Withington

Manchester M20 4BX

United Kingdom

Tel: +44-161-446-3439

Fax: +44-161-446-8401

e-mail: mark.Saunders@christie.nhs.uk 


\section{ABSTRACT}

\section{PURPOSE}

To evaluate the efficacy, safety and quality of life (QoL) of a short course of oxaliplatin plus capecitabine (XELOX) followed by single-agent capecitabine in patients with previously untreated, inoperable, metastatic colorectal cancer.

\section{METHODS}

Patients received intravenous oxaliplatin $130 \mathrm{mg} / \mathrm{m}^{2}$ on $\mathrm{d} 1$ plus oral capecitabine $1000 \mathrm{mg} / \mathrm{m}^{2}$ twice daily (bid) on d1-14 every 21 days for 4 cycles. Patients achieving stable disease (SD) or better then received capecitabine $1250 \mathrm{mg} / \mathrm{m}^{2}$ bid on $\mathrm{d} 1-14$ every 21 days until disease progression. The primary endpoint was progression-free survival (PFS).

\section{RESULTS}

Overall 21/45 (47\%) of patients responded to the initial XELOX chemotherapy whilst SD or better was documented in 76\%. Median PFS was 6.7 (95\% CI 5.7-9.6) months, and median overall survival (OS) was 20.5 (95\% CI 13.1-28.1) months. In the 34 patients who then received capecitabine maintenance therapy, the median PFS was 8.1 (95\% CI 6.211.8) months and median OS was 23.1 (95\% CI 17.8-28.5) months. A marked reduction in the vast majority of all grades of adverse event occurred on switching from initial XELOX to maintenance capecitabine chemotherapy including grade 1-2 (77\% vs. $47 \%)$ and grade 3 (7\% vs. 3\%) neuropathy, diarrhoea and lethargy. 


\section{CONCLUSIONS}

Short-course XELOX followed by capecitabine maintenance therapy provides an active and well-tolerated treatment option for patients with previously untreated metastatic colorectal cancer. A median OS of more than 20 months is promising and by limiting the number of oxaliplatin infusions, this approach minimises the risk of unwanted cumulative neurotoxicity, is cheaper and more convenient for both patients and healthcare providers.

250 words (maximum 250)

Keywords: metastatic colorectal cancer; capecitabine; oxaliplatin; stop-and-go strategy; quality of life 


\section{INTRODUCTION}

Over the past decade, several new cytotoxic and targeted agents have become available for the treatment of patients with colorectal cancer. However, the optimal duration and sequence of therapy remains to be determined. Previously, the UK Medical Research Council Colorectal Cancer Group compared an intermittent regimen of 5fluorouracil/leucovorin (5-FU/LV) (i.e. 12 weeks of therapy with retreatment on disease progression) with conventional continuous 5-FU/LV in patients with metastatic colorectal cancer [1]. This study showed conclusively that intermittent treatment was as effective as continuous treatment, but that patients receiving the intermittent regimen had a better quality of life (QoL).

Oxaliplatin can be combined with either 5-FU/LV [2-4] or the oral fluoropyrimidine, capecitabine $\left(\right.$ Xeloda $\left.^{\circledR}\right)$ [5-7], to give an effective first-line regimen for patients with metastatic colorectal cancer. However, oxaliplatin can cause sensory neuropathy, a cumulative, dose-related toxicity, which is generally observed after 4 to 6 months of therapy $[2,3,8]$. The median time to response with oxaliplatin-based regimens, however, generally occurs earlier ( 2 to 5 months) $[4,8]$. It may therefore be possible to devise a regimen which achieves maximum treatment effect before cumulative neurotoxicity appears. Support for this concept has recently come from the OPTIMOX-1 and OPTIMOX2 studies, which documented the efficacy of a "stop-and-go" strategy consisting of FOLFOX-7 for 12 weeks, followed by 5-FU/LV maintenance therapy for 24 weeks, and reintroduction of FOLFOX-7 thereafter, $[9,10]$. The GISCAD study further demonstrated 
the feasibility and efficacy of an intermittent irinotecan-based regimen (i.e. FOLFIRI for 8 weeks alternating with an 8 -week chemotherapy-free interval) [11].

The XELoda QUALIty-of-life study was conducted to evaluate the efficacy, safety and QoL of a short course of oxaliplatin in combination with capecitabine (XELOX) followed by maintenance treatment with single-agent capecitabine in patients with previously untreated, inoperable metastatic colorectal cancer. The aim of this treatment strategy was to elicit an initial response with the XELOX regimen, and then maintain this response with a simpler, better-tolerated single-agent regimen which might also improve patient QoL. Both XELOX [5-7] and capecitabine monotherapy $[12,13]$ have established efficacy in the firstline treatment of metastatic colorectal cancer, but have not been investigated in this manner previously. 


\section{PATIENTS AND METHODS}

\section{Study design}

This single-arm, open-label, phase II study was conducted at 2 centres in the United Kingdom. It was performed in accordance with the Declaration of Helsinki and Good Clinical Practice Guidelines. The protocol was reviewed and approved by the ethics committee at each participating site. Written informed consent was obtained from all patients prior to study participation.

\section{Patient population}

Ambulatory patients aged $\geq 18$ years with non-resectable locally advanced or metastatic colorectal cancer were enrolled. Patients were required to have tumours which were measurable or evaluable according to Response Evaluation Criteria in Solid Tumors (RECIST) criteria [14]. No previous chemotherapy for metastatic disease was permitted. Adjuvant chemotherapy, if administered, must have been completed $>4$ months prior to trial entry and could include bolus 5-FU but not infusional 5-FU, oxaliplatin or irinotecan. Patients were required to have a WHO performance status of $0-2$, a life expectancy of $>3$ months and normal renal, hepatic, and haematological function.

Exclusion criteria included: concurrent uncontrolled medical illness; other previous or current malignant disease likely to interfere with study treatment; partial or complete bowel obstruction; chronic diarrhoea or inflammatory bowel disease; inability to comply with QoL assessments; regular/uncontrolled angina or cardiac arrhythmias; brain metastases; pregnant or lactating women; and peripheral neuropathy. 


\section{Treatment plan and salvage therapy}

All patients received intravenous oxaliplatin $130 \mathrm{mg} / \mathrm{m}^{2}$ as a 120 -minute infusion on day 1 plus oral capecitabine $1000 \mathrm{mg} / \mathrm{m}^{2}$ twice daily on days $1-14$ every 21 days (XELOX) for 4 cycles (i.e. 12 weeks). Patients achieving at least stable disease in response to XELOX then received oral capecitabine $1250 \mathrm{mg} / \mathrm{m}^{2}$ twice daily on days $1-14$ every 21 days until disease progression at the discretion of the investigator.

If, in the opinion of the treating consultant, an alternative treatment modality was indicated at any stage, it could be offered to patients (e.g. hepatic resection, palliative radiotherapy, bypass surgery). It was anticipated that this would involve stopping trial treatment in most cases, but trial treatment could be continued after the other treatment if appropriate.

If the patient responded to trial treatment but stopped for reasons other than disease progression, they could be re-challenged with XELOX upon disease progression at the discretion of the investigator. When disease progression occurred on or after trial treatment, options for further chemotherapy or symptomatic treatment were considered according to local policy.

\section{Assessments}

Medical history; physical examination; WHO performance status; full blood count; and blood biochemistry were assessed within 4 weeks of the start and every 3 weeks of study treatment:

Tumour assessments, using CT or MRI scans, were performed within 4 weeks prior to starting study treatment. They were repeated every 12 weeks thereafter until disease progression was documented. RECIST guidelines [14] were used to define all responses. 
Adverse events were evaluated using the National Cancer Institute Common Terminology Criteria for Adverse Events (version 3) every 3 weeks during treatment.

\section{Quality of life}

QoL was assessed using the European Organization for Research and Treatment of Cancer (EORTC) questionnaire QLQ-C30 [15] together with the colorectal cancer-specific module QLQ-CR38 [16]. QoL questionnaires were completed in the clinic at baseline (prior to study registration), 6 weeks, 12 weeks, 18 weeks, 24 weeks and then 12 -weekly thereafter. When the QoL assessment coincided with a treatment cycle, the questionnaire was to be completed before treatment was given. Patients were asked to complete all questionnaires (i.e. even if they refused on a previous occasion or did not complete study treatment) and without conferring with friends or relatives. A patient diary was also provided to record details of medication taken and any adverse events/comments.

\section{Statistical analysis}

Combination chemotherapy with oxaliplatin and either 5-FU or capecitabine would be expected to achieve a progression-free survival (PFS) of 7 to 9 months $[4,8]$. In the present study, the aim was to achieve a similar PFS even though oxaliplatin was stopped after 12 weeks of treatment. This statistical analysis was based on an extrapolation of Gehan's 2 step model and was formulated after discussion with Dr R. Swindell (Head of Statistics, Christie Hospital).

The primary efficacy endpoint was PFS, which was defined as the interval from the first day of treatment to first evidence of clinical / radiological progression or death. Secondary 
objectives were comparative assessments of toxicity and QoL between XELOX and singleagent capecitabine. Secondary endpoints were objective response rate, compliance, and overall survival, which was defined as the time from registration to death from any cause. Time to event data were analysed using the Kaplan-Meier method. Median values with 95\% confidence intervals (CI) were presented. 


\section{RESULTS}

Between 14 February 2005 and 20 February 2006, a total of 45 patients were enrolled in the study. Patients' baseline characteristics are shown in Table 1.

\section{Treatment exposure}

A study flow chart for all 45 patients is presented in Figure 1. Thirty-five patients received 4 cycles of XELOX, of whom 31 received capecitabine maintenance therapy. The remaining 10 patients received less than 4 cycles of XELOX, for the following reasons: disease-related death/deterioration during treatment $(n=4)$; allergic-type reaction to oxaliplatin $(n=3)$; grade 3 toxicity $(n=1)$; did not meet inclusion criteria $(n=1)$; or patient withdrawal after 1 cycle of chemotherapy $(n=1)$. Three of these 10 patients went on to receive capecitabine maintenance therapy. XELOX was reintroduced at disease progression in 14 patients.

Enrolled patients $(n=45)$ received a median of 4 (range 0 to 4$)$ cycles of XELOX and a median of 3 (range 0 to 16) cycles of capecitabine maintenance therapy. Patients who received any capecitabine maintenance therapy $(n=34)$ received a median of 4 (range 1 to 16) cycles. Patients who had XELOX $(n=14)$ reintroduced received a median of 4 (range 2 to 8) cycles of XELOX.

\section{Efficacy}

Efficacy data were available for all 45 patients. Three patients received only 1 cycle of chemotherapy followed by clinical deterioration; one patient's disease was not measurable, whilst a further patient did not receive chemotherapy since their liver function deteriorated 
after screening. Since it was our intention to treat all patients that were entered into the study, all 45 patients were included in the analysis. A complete response was documented in $1(2 \%)$ patient and partial responses in $20(44 \%)$ patients, giving an overall response rate of $47 \%$. A further $13(29 \%)$ patients had stable disease giving a clinical benefit (i.e. stable disease or better) of $76 \%$. Median PFS in the total evaluable patient population was 6.7 (95\% CI 5.7-9.6) months, and overall survival was 20.5 (95\% CI 13.1-28.1) months. Kaplan-Meier curves for PFS and OS are shown in Figures 2 and 3, respectively. In the 34 patients who received XELOX followed by capecitabine maintenance therapy, the median PFS was 8.1 (95\% CI 6.2-11.8) months and median overall survival was 23.1 (95\% CI 17.8-28.5) months. In the 14 patients in whom XELOX was reintroduced at disease progression, median PFS was 8.1 (95\% CI 5.8-11.0) months and median overall survival was 23.1 (95\% CI 17.8-28.5) months from the start of the trial; median overall survival was $11.6(95 \%$ CI 8.7-16.3) months from restarting XELOX.

Four $(9 \%)$ of the 45 patients enrolled had tumour downsizing and were able to undergo liver resection; all of these patients were alive at last follow-up and 3 had no signs of disease recurrence or progression.

\section{Quality of life}

The following number of patients completed QoL forms at each study time-point: baseline $(n=41) ; 6$ weeks $(n=27) ; 12$ weeks $(n=23) ; 18$ weeks $(n=12) ; 24$ weeks $(n=18) ; 36$ weeks $(\mathrm{n}=11)$; and 48 weeks $(\mathrm{n}=10)$.

No differences in QoL were observed during treatment with XELOX (up to week 12) and single-agent capecitabine (after week 12). To illustrate this, scores for the overall health domain of the EORTC QLQ-C30 during the course of the study are shown in Figure 4. 


\section{Safety}

Safety data were available for 44 patients who received initial therapy with XELOX, and for 34 patients who received follow-on capecitabine maintenance therapy. The most frequent adverse events reported in these patient cohorts are presented in Table 2. No grade 4 adverse events were documented during the trial.

During initial XELOX therapy, most adverse events were grade 1 or 2 in severity. The most frequent grade 3 clinical adverse events were: diarrhoea (16\%); lethargy (12\%); neuropathy (7\%); anorexia (5\%); nausea (2\%); vomiting (2\%); and hand-foot syndrome (2\%). No grade 3 or 4 haematological adverse events were documented.

There was a marked reduction in the frequency of most grade 1-2 and grade 3 adverse events after switching to capecitabine maintenance therapy (Table 2). The only exceptions were abnormal liver function tests and hand-foot syndrome, which increased in frequency because of the higher capecitabine dose used during maintenance therapy. The only grade 3 adverse events which occurred during capecitabine maintenance therapy were hand-foot syndrome (9\%) and neuropathy (3\%). Neuropathy documented during capecitabine maintenance therapy is likely to have been residual toxicity after the use of oxaliplatin.

Treatment was discontinued because of adverse events during initial XELOX therapy in 4 patients (allergic-type reactions to oxaliplatin, $n=3$; grade 3 anorexia/lethargy, $n=1$ ); none of the patients who experienced an allergic-type reaction to oxaliplatin had pain on infusion. During capecitabine maintenance therapy, 2 patients discontinued treatment because of adverse events (hand-foot syndrome, $n=1$; renal impairment, $n=1$ ). No treatment-related deaths occurred. 


\section{DISCUSSION}

Despite the recent introduction of several new cytotoxic and targeted agents with proven efficacy in the treatment of patients with metastatic colorectal cancer, many questions remain regarding their use. These include the optimal duration of first-line therapy and the management of treatment-related toxicity. The present study shows that a short course of XELOX followed by maintenance therapy with single-agent capecitabine produces a favourable rate of disease control and duration of survival in patients with metastatic colorectal cancer. These findings suggest that a short course of oxaliplatin-based chemotherapy elicits a tumour response, which can then be maintained by a simpler maintenance regimen. The validity of this "stop-and-go" strategy has also recently been demonstrated in the OPTIMOX-1 study which showed that FOLFOX-7 for 6 cycles followed by 5-FU/LV for 12 cycles followed by reintroduction of FOLFOX-7 had similar efficacy to continuous FOLFOX-4, but with a greatly reduced risk of grade 3/4 toxicity [9].

The good tolerability profile of the present treatment strategy was notable. Limiting the exposure to XELOX appeared to reduce the risk of severe adverse events; no grade 4 clinical adverse events or grade 3 or 4 haematological adverse events were documented in the present study. Grade 3 neuropathy also occurred infrequently (7\% of patients), a rate that compares favourably with rates reported in previous large phase III studies of continuous XELOX $(4 \%, 18 \%, 8 \%)$ [5-7]. Switching to single-agent capecitabine was also accompanied by a marked reduction in the frequency of most adverse events (e.g. grade 3 lethargy $12 \%$ vs. $0 \%$ ) and grade 3 diarrhoea $16 \%$ vs. $0 \%$ ), confirming once again the tolerability benefits of this approach to therapy. 
Despite the improvement in tolerability evident after switching to single-agent capecitabine, no clinically meaningful QoL differences were detected between the XELOX and maintenance phases of therapy. This may have been because of residual toxicity (e.g. parasthesia, lethargy, diarrhoea) from initial XELOX therapy manifesting during the maintenance phase. Alternatively, a steady decline in the number of patients completing the QoL questionnaires may have influenced the outcome. This pattern of attrition, however, is common in the palliative setting and is similar to that reported in other studies of patients with metastatic colorectal cancer $[17,18]$. Although not captured by the EORTC questionnaires, several other relevant $\mathrm{QoL}$ and pharmacoeconomic benefits were evident with the regimen tested. These included the improved convenience of only 4 initial infusions of oxaliplatin to patients, medical staff and pharmacy personnel, and the reduced direct medical costs of this regimen (i.e. fewer oxaliplatin infusions, less pharmacy and chemotherapy suite time).

Perhaps not surprisingly, the degree of benefit experienced by patients from our treatment strategy increased with number of cycles completed. Obviously this could also reflect the biology of the disease in that those patients with a less aggressive cancer did better. Median PFS was 6.7 months in the total evaluable patient population, which increased to 8.1 months in patients who completed or partially completed both XELOX and capecitabine treatment phases. In the absence of a control group, it is of interest that these data, particularly those from the last patient cohort, compare favourably with recent phase III studies of continuous first-line XELOX in patients with metastatic colorectal cancer [5-7]. 
In these studies, median PFS ranged from 7.3 to 8.9 months and median overall survival ranged from 18.1 to 19.9 months.

Although not a formal part of the study treatment plan, some of our patients (31\%) went on to receive further XELOX on disease progression. The median PFS in this patient cohort was 8.1 months and median overall survival was 23.1 months, which is similar to the findings of the OPTIMOX-1 study which tested a similar 5-FU-based regimen (8.7 and 21.2 months, respectively) [9]. The feasibility of reintroducing oxaliplatin was questioned by the OPTIMOX-1 investigators as only $40 \%$ of patients completed this stage of study treatment. It is interesting to note, however, that a separate post hoc analysis of the OPTIMOX-1 data revealed that oxaliplatin reintroduction was a significant and independent predictor of improved overall survival [19]. The results of other ongoing studies (i.e. DREAM, CONCEPT, OASIS), which are investigating various stop-and-go treatment strategies with oxaliplatin-based regimens and targeted agents, will help to confirm the validity of this approach.

In conclusion, short-course XELOX followed by capecitabine maintenance therapy provides an effective treatment option for patients with previously untreated metastatic colorectal cancer. By limiting the number of oxaliplatin infusions, this approach minimises the risk of unwanted cumulative neurotoxicity, lethargy and diarrhoea plus is convenient to both patients and healthcare providers. It is also cheaper in terms of drug costs and administration, which is becoming even more of a pressing issue in all health economies. 


\section{ACKNOWLEDGMENTS}

Roche provided an educational grant for administration of the XelQuali trial.

\section{DISCLOSURES}

None 


\section{REFERENCES}

1. Maughan TS, James RD, Kerr DJ, Ledermann JA, Seymour MT, Topham C, McArdle C, Cain D, Stephens RJ; Medical Research Council Colorectal Cancer Group (2003) Comparison of intermittent and continuous palliative chemotherapy for advanced colorectal cancer: a multicentre randomised trial. Lancet 361:457-464

2. Goldberg RM, Sargent DJ, Morton RF, Fuchs CS, Ramanathan RK, Williamson SK, Findlay BP, Pitot HC, Alberts SR (2004) A randomized controlled trial of fluorouracil plus leucovorin, irinotecan, and oxaliplatin combinations in patients with previously untreated metastatic colorectal cancer. J Clin Oncol 22:23-30

3. Goldberg RM, Sargent DJ, Morton RF, Fuchs CS, Ramanathan RK, Williamson SK, Findlay BP, Pitot HC, Alberts S (2006) Randomized controlled trial of reduced-dose bolus fluorouracil plus leucovorin and irinotecan or infused fluorouracil plus leucovorin and oxaliplatin in patients with previously untreated metastatic colorectal cancer: a North American Intergroup Trial. J Clin Oncol $24: 3347-3353$

4. de Gramont A, Figer A, Seymour M, Homerin M, Hmissi A, Cassidy J, Boni C, Cortes-Funes H, Cervantes A, Freyer G, Papamichael D, Le Bail N, Louvet C, Hendler D, de Braud F, Wilson C, Morvan F, Bonetti A (2000) Leucovorin and fluorouracil with or without oxaliplatin as first-line treatment in advanced colorectal cancer. J Clin Oncol 18:2938-2947

5. Cassidy J, Clarke S, Díaz-Rubio E, Scheithauer W, Figer A, Wong R, Koski S, Lichinitser M, Yang TS, Rivera F, Couture F, Sirzén F, Saltz L (2008) Randomized phase III study of capecitabine plus oxaliplatin compared with fluorouracil/folinic acid plus oxaliplatin as first-line therapy for metastatic colorectal cancer. J Clin Oncol 26:2006-2012

6. Díaz-Rubio E, Tabernero J, Gómez-España A, Massutí B, Sastre J, Chaves M, Abad A, Carrato A, Queralt B, Reina JJ, Maurel J, González-Flores E, Aparicio J, Rivera F, Losa F, Aranda E; Spanish Cooperative Group for the Treatment of Digestive Tumors Trial (2007) Phase III trial of capecitabine and oxaliplatin (XELOX) vs continuous infusion 5-fluorouracil plus oxaliplatin (FUOX) as first-line therapy in metastatic colorectal cancer: final report of the Spanish TTD group trial. J Clin Oncol 25:4224-4230

7. Ducreux M, Bennouna J, Hebbar M, Ychou M, Lledo G, Conroy T, Adenis A, Faroux R, Rebischung C, Douillard J (2007) Efficacy and safety findings from a randomized phase III study of capecitabine $(\mathrm{X})$ + oxaliplatin $(\mathrm{O})(\mathrm{XELOX})$ vs. infusional 5- FU/LV + O (FOLFOX-6) for metastatic colorectal cancer (MCRC). J Clin Oncol 25;18S (suppl, abstract 4029) 
8. Giacchetti S, Perpoint B, Zidani R, Le Bail N, Faggiuolo R, Focan C, Chollet P, Llory JF, Letourneau Y, Coudert B, Bertheaut-Cvitkovic F, Larregain-Fournier D, Le Rol A, Walter S, Adam R, Misset JL, Lévi F (2000) Phase III multicenter randomized trial of oxaliplatin added to chronomodulated fluorouracil-leucovorin as first-line treatment of metastatic colorectal cancer. J Clin Oncol 18:136-147

9. Tournigand C, Cervantes A, Figer A, Lledo G, Flesch M, Buyse M, Mineur L, Carola E, Etienne PL, Rivera F, Chirivella I, Perez-Staub N, Louvet C, André T, Tabah-Fisch I, de Gramont A (2006) OPTIMOX1: a randomized study of FOLFOX4 or FOLFOX7 with oxaliplatin in a stop-and-Go fashion in advanced colorectal cancer: a GERCOR study. J Clin Oncol 24:394-400

10. Maindrault-Goebel F, Lledo G, Chibaudel B, Mineur L, Andre T, Bennamoun M, Mabro M, Artru P, Louvet C, De Gramont A (2006) OPTIMOX2, a large randomized phase II study of maintenance therapy or chemotherapy-free intervals (CFI) after FOLFOX in patients with metastatic colorectal cancer (MRC): a GERCOR study. J Clin Oncol 24 (18S; abstract 3504)

11. Labianca R, Floriani I, Cortesi E, Isa L, Zaniboni A, Marangolo M, Frontini L, Barni S, Beretta GD, Sobrero A, Italian Group for the Study of Digestive Tract Cancers (2006) Alternating versus continuous "FOLFIRI" in advanced colorectal cancer (ACC): A randomized "GISCAD" trial J Clin Oncol 24 (18S; abstract 3505)

12. Hoff PM, Ansari R, Batist G, Cox J, Kocha W, Kuperminc M, Maroun J, Walde D, Weaver C, Harrison E, Burger HU, Osterwalder B, Wong AO, Wong R (2001) Comparison of oral capecitabine versus intravenous fluorouracil plus leucovorin as first-line treatment in 605 patients with metastatic colorectal cancer: results of a randomized phase III study. J Clin Oncol 19:2282-2292

13. Van Cutsem E, Twelves C, Cassidy J, Allman D, Bajetta E, Boyer M, Bugat R, Findlay M, Frings S, Jahn M, McKendrick J, Osterwalder B, Perez-Manga G, Rosso R, Rougier P, Schmiegel WH, Seitz JF, Thompson P, Vieitez JM, Weitzel C, Harper P; Xeloda Colorectal Cancer Study Group (2001) Oral capecitabine compared with intravenous fluorouracil plus leucovorin in patients with metastatic colorectal cancer: results of a large phase III study. J Clin Oncol 19:4097-4106

14. Therasse P, Arbuck SG, Eisenhauer EA, Wanders J, Kaplan RS, Rubinstein L, Verweij J, Van Glabbeke M, van Oosterom AT, Christian MC, Gwyther SG (2000) New guidelines to evaluate the response to treatment in solid tumors. European Organization for Research and Treatment of Cancer, National Cancer Institute of the United States, National Cancer Institute of Canada. J Natl Cancer Inst 92:205-216

15. Aaronson NK, Ahmedzai S, Bergman B, Bullinger M, Cull A, Duez NJ, Filiberti A, Flechtner H, Fleishman SB, de Haes JC (1993) The European Organization for Research and Treatment of Cancer 
QLQ-C30: a quality-of-life instrument for use in international clinical trials in oncology. J Natl Cancer Inst 85:365-376

16. Sprangers MA, te Velde A, Aaronson NK (1999). The construction and testing of the EORTC colorectal cancer-specific quality of life questionnaire module (QLQ-CR38). European Organization for Research and Treatment of Cancer Study Group on Quality of Life. Eur J Cancer 35:238-247

17. Cunningham D, Pyrhonen S, James RD, , Punt CJ, Hickish TF, Heikkila R, Johannesen TB, Starkhammar H, Topham CA, Awad L, Jacques C, Herait P (1998) Randomised trial of irinotecan plus supportive care versus supportive care alone after fluorouracil failure for patients with metastatic colorectal cancer. Lancet 352:1413-1418

18. Hobday TJ, Kugler JW, Mahoney MR, Sargent DJ, Sloan JA, Fitch TR, Krook JE, O'Connell MJ, Mailliard JA, Tirona MT, Tschetter LK, Cobau CD, Goldberg RM (2002) Efficacy and quality-oflife data are related in a phase II trial of oral chemotherapy in previously untreated patients with metastatic colorectal carcinoma. J Clin Oncol 20:4574-4580

19. de Gramont A, Buyse M, Abrahantes JC, Burzykowski T, Quinaux E, Cervantes A, Figer A, Lledo G, Flesch M, Mineur L, Carola E, Etienne PL, Rivera F, Chirivella I, Perez-Staub N, Louvet C, André T, Tabah-Fisch I, Tournigand C (2007) Reintroduction of oxaliplatin is associated with improved survival in advanced colorectal cancer. J Clin Oncol 25:3224-3229 
Table 1. Baseline patient characteristics $(n=45)$

\begin{tabular}{|c|c|c|}
\hline Characteristic & No. & $\%$ \\
\hline \multicolumn{3}{|l|}{ Gender } \\
\hline Male & 28 & 62 \\
\hline Female & 17 & 38 \\
\hline \multicolumn{3}{|l|}{ Age, years } \\
\hline Median (range) & $58(38-79)$ & \\
\hline \multicolumn{3}{|c|}{ WHO performance status } \\
\hline 0 & 20 & 44 \\
\hline $1-2$ & 25 & 56 \\
\hline \multicolumn{3}{|l|}{ Metastatic sites(s) } \\
\hline Liver & 35 & 78 \\
\hline Lymph nodes & 17 & 38 \\
\hline Lung & 16 & 36 \\
\hline Adrenal & 2 & 4 \\
\hline Ovary & 2 & 4 \\
\hline Omentum & 2 & 4 \\
\hline Other & 3 & 7 \\
\hline
\end{tabular}


Table 2. Most frequent adverse events (>20\% of patients)

\begin{tabular}{|c|c|c|c|c|c|c|c|c|}
\hline \multirow[t]{3}{*}{ Adverse event } & \multicolumn{4}{|c|}{$\begin{array}{l}\text { Initial XELOX } \\
\qquad(n=43)\end{array}$} & \multicolumn{4}{|c|}{$\begin{array}{l}\text { Capecitabine maintenance } \\
\qquad(\mathrm{n}=34)\end{array}$} \\
\hline & \multicolumn{2}{|c|}{ Grade 1-2 } & \multicolumn{2}{|c|}{ Grade 3} & \multicolumn{2}{|c|}{ Grade 1-2 } & \multicolumn{2}{|c|}{ Grade 3} \\
\hline & No. & $\%$ & No. & $\%$ & No. & $\%$ & No. & $\%$ \\
\hline \multicolumn{9}{|l|}{ Clinical/laboratory events } \\
\hline Neuropathy & 33 & 77 & 3 & 7 & 16 & 47 & 1 & 3 \\
\hline Lethargy & 33 & 77 & 5 & 12 & 27 & 79 & 0 & 0 \\
\hline Diarrhoea & 21 & 49 & 7 & 16 & 13 & 38 & 0 & 0 \\
\hline Nausea & 27 & 63 & 1 & 2 & 11 & 32 & 0 & 0 \\
\hline Hand-foot syndrome & 15 & 35 & 1 & 2 & 17 & 50 & 3 & 9 \\
\hline Vomiting & 13 & 30 & 1 & 2 & 4 & 12 & 0 & 0 \\
\hline Mucositis & 12 & 28 & 0 & 0 & 3 & 9 & 0 & 0 \\
\hline Infection & 11 & 26 & 1 & 2 & 9 & 26 & 0 & 0 \\
\hline Constipation & 10 & 23 & 1 & 2 & 3 & 9 & 0 & 0 \\
\hline Abnormal liver function tests & 13 & 30 & 0 & 0 & 19 & 56 & 0 & 0 \\
\hline \multicolumn{9}{|l|}{ Haematological events } \\
\hline Anaemia & 19 & 44 & 0 & 0 & 14 & 41 & 0 & 0 \\
\hline Thrombocytopenia & 14 & 33 & 0 & 0 & 9 & 26 & 0 & 0 \\
\hline Neutropenia & 12 & 28 & 0 & 0 & 5 & 15 & 0 & 0 \\
\hline Leukopenia & 10 & 23 & 0 & 0 & 6 & 18 & 0 & 0 \\
\hline
\end{tabular}

Abbreviations: XELOX, capecitabine and oxaliplatin. 


\section{FIGURE CAPTIONS}

Figure 1. Patient treatment schema

Figure 2. Progression-free survival for all patients $(n=45)$. PP graphs included

Figure 3. Overall survival for all patients $(n=45)$. PP graphs included

Figure 4. EORTC QLQ-C30 overall health score (which uses a 2 to 14-point subscale).

The vertical line shows the range of scores and the horizontal bar shows the median value at each given time-point. 
Figure 1.

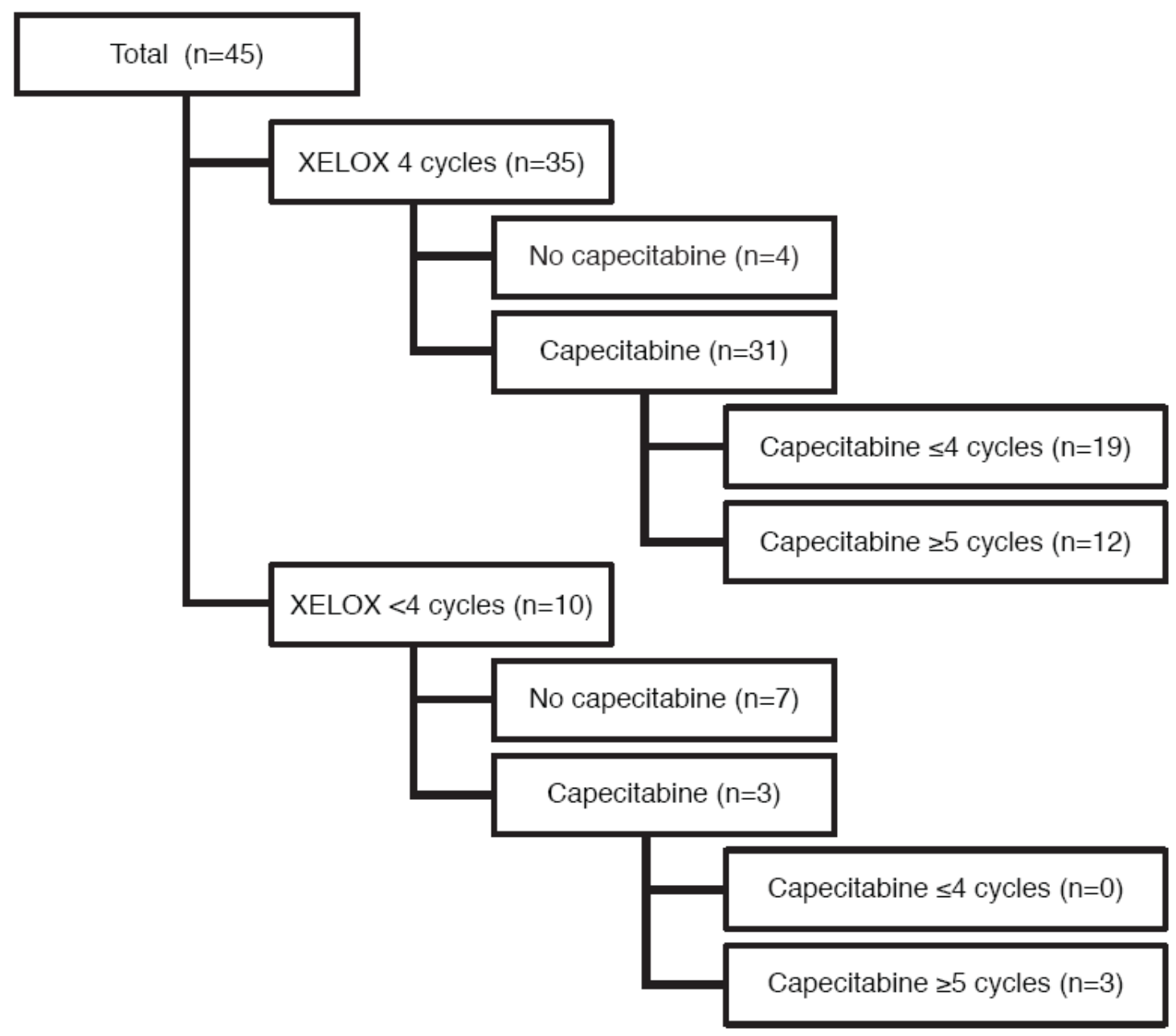


Figure 2.

See PDF 
Figure 3.

See PDF 
Figure 4.

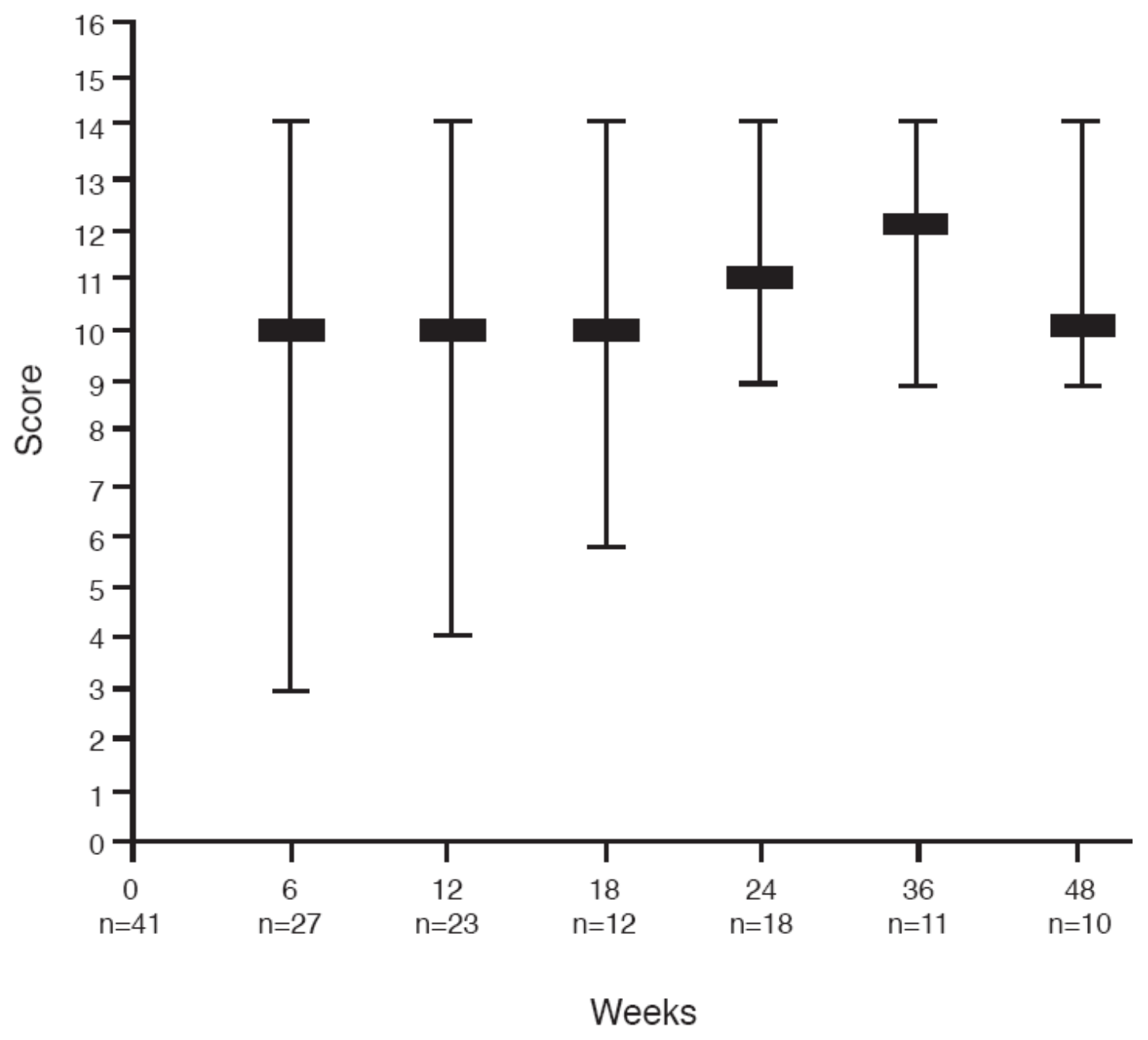

